\section{Haemolytic streptococcal gangrene and non-steroidal anti-inflammatory drugs}

All patients with necrotising fasciitis seen at this hospital over 10 years were reviewed. Six cases were found in which non-steroidal antiinflammatory drugs were suspected of having contributed to the infection; these cases are reported below.

\section{Patients, methods, and results}

The records of all 31 patients seen at this hospital during 1972-82 with a discharge diagnosis of necrotising fasciitis were reviewed. We considered for analysis only those who fulfilled strict criteria for acute dermal gangrene ${ }^{1}$ - that is, with a history of rapidly spreading cutaneous infection and evidence of extensive subcutaneous necrosis and oedema but sparing of underlying muscle. To select patients who had not had a predisposing condition we excluded those with postoperative necrotising fasciitis or suprainfection of chronic venous or arterial leg ulcers and those with any debilitating underlying disease that could have affected normal defence mechanisms. Thus six previously healthy patients in whom severe necrotising fasciitis had developed apparently spontaneously or after minor trauma remained for analysis.

A history of recent minor trauma was noted in four of the six patients (table). When the initial symptoms arose non-specific inflammation or superficial phlebitis was diagnosed in all six cases and therapeutic dosages of non-steroidal anti-inflammatory drugs prescribed. Two patients were subsequently given steroids because of continued inflammation. Four patients received more than one anti-inflammatory agent, of whom two received a combination of three drugs including aspirin. Four to 10 days elapsed between the initial symptoms and referral to hospital, when extensive necrotising fasciitis was diagnosed.

In all patients except one (case 1), to whom benzylpenicillin had been given for 24 hours before admission, a Lancefield's group A $\beta$-haemolytic streptococcus was recovered from cultures of the blisters or from areas of necrosis blood cultures in two cases also yielded this organism. Treatment included intravenous administration of aqueous benzylpenicillin in high dose (12-20 MU/day), fluid replacement, and early surgery. One patient (case 5), with necrotising fasciitis extending to the lateral chest wall, died of septic shock within 24 hours after admission despite immediate surgery and aggressive supportive therapy. The five other patients survived after a prolonged stay in hospital that entailed multiple re-explorations of infected areas, excision of necrotic tissue, and eventual skin grafting in four cases.

\section{Comment}

Necrotising fasciitis is a potentially fatal infection of soft tissue that usually occurs after trauma or surgery. ${ }^{12}$ The group $A$ haemolytic streptococcus (Streptococcus pyogenes) has long been recognised as an agent of this infection and still accounts for many cases. $^{3}$ Patients with the infection often have serious underlying diseases, including diabetes mellitus, severe cardiovascular disease, hepatic cirrhosis, and conditions requiring long term treatment with steroids. ${ }^{1-3}$ No underlying disease was present in our patients, but all had been given non-steroidal anti-inflammatory drugs. The sequence of events suggested that these compounds affected the development or extension of the disease in our patients as no other drugs were given Activation of latent infections in debilitated patients treated with non-steroidal anti-inflammatory drugs was suspected by Solomon. In vitro studies support this hypothesis by suggesting that functions mediated by granulocytes, which are critical in the early stages of host defence against infection, may be impaired by non-steroidal anti-inflammatory drugs. In vitro chemotaxis, phagocytosis, and bactericidal activity of granulocytes are reduced by these drugs. Solberg et al observed reduced in vitro killing of Staphylococcus aureus and streptococcus group B by granulocytes incubated with phenylbutazone. ${ }^{5}$ Whether these effects occur in vivo in patients given non-steroidal anti-inflammatory drugs remains to be determined.

Our observations suggest that non-steroidal anti-inflammatory drugs should be used cautiously when infection is suspected in a patient with an apparently benign "non-specific" inflammatory lesion of the skin.

We thank Dr Jonathan L Meakins (McGill University, Montreal) for his advice.

1 Dellinger EP. Severe necrotizing soft tissue infections: multiple disease entities requiring a common approach. f $A M A 1981 ; 246$ : 1717-21 requiring a common approach. $\mathcal{F} A M A$. Diagnosis, clinical course, and treatment of
acute dermal gangrene. Br $\mathcal{F}$ Surg $1975 ; 62: 364-72$.

3 Aitken DR, Mackett T, Smith LL. The changing pattern of hemolytic streptococcal gangrene. Arch Surg 1982;117:561-7.

4 Solomon L. Activation of latent infection by indomethacin: a report of three cases. Br Med f 1966; ;:961-2

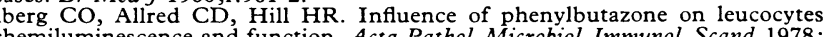
$86: 165-71$.

(Accepted 28 February 1985)

Intensive Care Unit, Hôpital Henri Mondor, Université Paris XII, 94010 Créteil, France

CHRISTIAN J L BRUN-BUISSON, MD, senior registrar

MICHEL SAADA, MD, houseman

PATRICK TRUNET, MD, senior registrar

MAURICE RAPIN, MD, professor

Department of Dermatology, Hôpital Henri Mondor

JEAN-CLAUDE ROUJEAU, MD, senior registrar

JEAN REVUZ, $M D$, professor

Correspondence to: Dr C J L Brun-Buisson.

\section{Smoking, sugar, and inflammatory bowel disease}

Previous studies have suggested that an association exists between smoking habit and both ulcerative colitis ${ }^{12}$ and Crohn's disease. ${ }^{3}$ We reported studies of the diets before illness of patients who developed both types of inflammatory bowel disease ${ }^{4}$ : the patients who developed Crohn's disease had a high intake of refined sugar and a low intake of fibre from fruit. We now report the smoking behaviour of these patients and relate it to their dietary habits.

\section{Subjects, methods, and results}

We studied 30 consecutive patients with ulcerative colitis and 30 consecutive patients with Crohn's disease. All were interviewed within three months of diagnosis. The two groups of control subjects had recently attended a fracture clinic but were otherwise healthy. They were matched for age (to

Clinical presentation of patients with necrotising fasciitis associated with non-steroidal anti-inflammatory drugs

\begin{tabular}{|c|c|c|c|c|c|c|c|c|c|}
\hline $\begin{array}{l}\text { Case } \\
\text { No }\end{array}$ & $\begin{array}{l}\text { Age/ } \\
\text { sex }\end{array}$ & Triggering event & $\begin{array}{c}\text { Initial } \\
\text { diagnosis }\end{array}$ & Drugs administered & $\begin{array}{l}\text { Delay* } \\
\text { (days) }\end{array}$ & Extent of necrotising fasciitis & $\begin{array}{l}\text { Culture for } \\
\text { group A } \\
\text { streptococcus } \\
\text { (skin/blood) }\end{array}$ & Complications & Outcome \\
\hline 1 & $34 / F$ & Heel graze & Phlebitis & Indomethacin, & 8 & Right calf and foot & $-1-$ & Shock & Survived \\
\hline 2 & $55 / \mathrm{F}$ & Unknown & Phlebitis & Diclofenac & 6 & Left calf and thigh & $+1-$ & Renal failure, & Survived \\
\hline 3 & $47 / F$ & Foot scar & Phlebitis & Indomethacin, & 6 & Right calf, foot, and thigh & $+1+$ & $\begin{array}{l}\text { thrombocytopenia } \\
\text { Renal failure }\end{array}$ & Survived \\
\hline 4 & $63 / \mathrm{F}$ & Rose thorn scratch & $\begin{array}{l}\text { Non-specific } \\
\text { inflammation }\end{array}$ & $\begin{array}{l}\text { Indomethacin, aspirin, } \\
\text { prednisone } 30 \mathrm{mg} / \text { day }\end{array}$ & 4 & Left arm and forearm & $+1+$ & Shock & Survived \\
\hline 5 & $70 / M$ & Unknown & $\begin{array}{l}\text { Non-specific } \\
\text { inflammation }\end{array}$ & Indomethacin & 4 & $\begin{array}{l}\text { Upper right arm and lateral } \\
\text { chest wall }\end{array}$ & $+1-$ & Shock & Died \\
\hline 6 & $43 / F$ & Insect bite & $\begin{array}{l}\text { Non-specific } \\
\text { inflammation }\end{array}$ & $\begin{array}{l}\text { Phenylbutazone, aspirin, } \\
\text { oxyphenbutazone, then } \\
\text { methylpredisolone }\end{array}$ & 10 & Left calf & $+1-+$ & & Survived \\
\hline
\end{tabular}

*Delay from triggering event to overt necrotising fasciitis and referral to hospital.
+ Staphylococcus aureus also isolated from cultures of skin blisters in this patient. 
within five years), sex, social class, and marital state. Both patients and controls were asked whether they currently smoked or whether they were former smokers and, if so, when they had given up. The patients were classified as smokers or non-smokers according to their habits at the time of onset of their symptoms. The diet of the patients and controls was determined by one dietitian. ${ }^{4}$ The significance of differences was calculated using the $\chi^{2}$ test or Student's $t$ test, as appropriate.

Twenty one of the patients with Crohn's disease smoked either cigarettes $(n=19)$ or a pipe $(n=2)$ compared with 10 of their controls (cigarettes $n=8$, pipe $n=2)\left(\chi^{2}=7 \cdot 126, p<0 \cdot 01\right)$. Only two of the patients with Crohn's disease and one of their controls were former smokers.

Of the 30 patients with ulcerative colitis, four smoked cigarettes, compared with 11 of the control group who smoked cigarettes and one who smoked a pipe $\left(\chi^{2}=5.455, p<0.05\right)$. Interestingly, 14 of the patients with ulcerative colitis had given up smoking a mean of 27 (SEM 7) months before the first symptoms of their disease. Only two of the controls were former smokers $\left(x^{2}=12 \cdot 273, \mathrm{p}<0.001\right)$.

There was no significant difference between smokers and non-smokers within the group of patients with Crohn's disease or when these patients were compared with their controls in the consumption of any dietary constituent, including sugar, dietary fibre, protein, fat, or energy intake. Similarly, there were no significant differences in dietary intake between smokers and non-smokers in the group of patients with ulcerative colitis or when these patients were compared with their smoking and non smoking controls. Furthermore, consumption of refined sugar was even greater among the patients with Crohn's disease $(n=9)$ who were non-smokers compared with the control patients $(\mathrm{n}=10)$ who were smokers (132 $v 85 \mathrm{~g}$ /day, $\mathrm{p}<0.05)$.

\section{Comment}

Our findings support the existence of a positive association between smoking and Crohn's disease. ${ }^{3}$ The data also agree with studies indicating a paucity of smokers among patients with ulcerative colitis. ${ }^{12}$

The patients with Crohn's disease consumed more refined sugar, regardless of their smoking habits. Indeed, the patients with Crohn's disease who were non-smokers consumed more sugar than those of their control group who were smokers. Thus, smoking and a diet characterised by a high intake of refined sugar appear to be independent positive associations with the development of Crohn's disease.

The patients with ulcerative colitis were three times less likely to smoke but seven times more likely to be former smokers than their controls. The possible aetiological importance of this association is strengthened by the fact that the patients with colitis who were former smokers had given up smoking a mean of only 27 months earlier, a relatively short interval considering that their average age at that time was 40 .

How smoking may influence susceptibility to inflammatory bowel disease remains unclear. Nevertheless, though smoking may confer some protection against ulcerative colitis, our data suggest that it may increase the risk of Crohn's disease.

1 Harries AD, Baird A, Rhodes J. Non-smoking: a feature of ulcerative colitis. Br 2 Jick H, Walker AM. Cigarette smoking and ulcerative colitis. N Engl 3 Med 2 Jick $H, W$, Walker AM. Cigarette smoking and ulcerative colitis. N Engl 3 Med
$1983 ; 308: 261-3$.
3 Somerville KW, Logan RFA, Edmond M, Langman MJS. Smoking and Crohn's
disease. Br Med $1984289: 954-6$. disease. $\mathrm{Br}$ Med $\mathcal{f} 1984$ 289:954-6.
Thornton JR, Emmett PM, Heaton $\mathrm{KW}$. Diet and Crohn's disease : characteristics
of the pre-illness diet. $\mathrm{Br}$ Med $\mathcal{f}$ 1979;ii:762-4.

5 Thornton JR, Emmett PM, Heaton KW. Diet and ulcerative colitis. Br Med 3
$1980 ; 280: 293$.

Accepted 6 March 1985)

Bristol Royal Infirmary, Bristol BS2 8HW

J R THORNTON, MD, MRCP, honorary senior registrar

P M EMMETT, BSC, SRD, senior dietitian

$\mathrm{K} W$ HEATON, MD, FRCP, reader in medicine

Correspondence to: Dr J R Thornton, St James's University Hospital, Leeds LS9 7TF.

\section{Intrauterine death during continuous subcutaneous infusion of insulin}

Continuous subcutaneous insulin infusion is an established technique for treating diabetics when tight control of blood glucose concentration is required. It has been recommended in the management of diabetes in pregnancy in well motivated patients difficult to control on conventional treatment. ${ }^{1}$

\section{Case report}

A 27 year old patient, dependent on insulin for 20 years, attended our prepregnancy clinic. ${ }^{2}$ She was on short and intermediate acting insulin twice daily, and blood glucose concentrations on this regimen showed pronounced fluctuations with glycosylated haemoglobin $\left(\mathrm{HbA}_{1}\right)$ concentration over $10^{\circ}$ " (normal $6-8^{\circ}$ ) despite her meticulous approach to treatment. She had had recurrent hypoglycaemia but no episodes of ketoacidosis for over 10 years.

She was started on continuous subcutaneous insulin infusion using a syringe pump operated by a battery that was designed to deliver a basal infusion and bolus doses before meals (CPI Betatron II Model 9200). Safety features included two alarms; one to indicate malfunction of the battery, the other to indicate an empty syringe or obstruction. This resulted in less pronounced fluctuations of blood glucose concentration and fewer hypoglycaemic episodes. $\mathrm{HbA}_{1}$ concentration decreased although we were unable to get it below $9^{\circ}$.".

She conceived, and the pregnancy progressed satisfactorily for 31 weeks. Mid-morning blood glucose concentration was $7 \mathrm{mmol} 1(126 \mathrm{mg} / 100 \mathrm{ml})$, $\mathrm{HbA}_{1}$ concentration $9 \cdot 1^{\prime \prime}$, on a total daily dose of insulin of about 50 units ( 28 units basal with a bolus of $5-15$ units before meals). One evening before going out she noticed that her blood glucose concentration at $6 \mathrm{pm}$ was high $(13 \mathrm{mmol} / 1(234 \mathrm{mg} / 100 \mathrm{ml})$ ) so she gave herself a boost of 15 units of insulin but did not test for ketones. At $7 \mathrm{pm}$ she changed the infusion, relocated the needle-the area round the infusion was slightly red-refilled the syringe, and checked the pump was recording correctly. At midnight she felt well, but, being very tired, omitted to test her blood glucose concentration. At 4 pm she awoke feeling nauseated and vomited repeatedly.

By morning her blood glucose concentration was $13 \mathrm{mmol} / 1(234 \mathrm{mg} /$ $100 \mathrm{ml}$ ), and despite advice to test for ketones when her blood glucose was high or if she was unwell, she did not do so. She realised that she had failed to "prime" the pump when she relocated the needle the night before-thus leaving the dead space in the tubing full of air-and she corrected this and gave herself a boost of insulin ( 15 units). By 11 am she was feeling wel and ate normally. She had not, however, felt the baby move since the previous evening and, although she suspected the baby was dead, did not report to hospital until late evening. On admission she appeared well, with no evidence of infection. Blood glucose concentration was $4 \mathrm{mmol} / 1(72 \mathrm{mg} /$ $100 \mathrm{ml}$ ) and she had ketonuria. Bicarbonate concentration next morning was $25 \mathrm{mmol}(\mathrm{mEq}) / 1$. Intrauterine death was confirmed, labour was induced, and a stillborn baby boy was delivered weighing $2 \cdot 28 \mathrm{~kg}$. The baby was slightly macrosomic, but postmortem examination showed no congenital abnormality.

\section{Comment}

Although the patient appeared competent in the use of the pump, she omitted to test for acetone and delayed reporting vomiting and lack of fetal movement. She received no basal insulin for 12 hours and effectively no insulin at all for about seven hours because she forgot to prime the pump. This presumably caused ketoacidosis, which although not severe was sufficient to kill the baby. The automatic alarm would not have been activated because the insulin was leaving the syringe without obstruction.

Pickup et al stopped infusion for nine hours to investigate what would happen if accidental failure of continuous subcutaneous infusion of insulin occurred. ${ }^{3}$ None of the nine patients became more than mildly unwell, although hydroxybutyrate concentrations rose progressively. Boulton et al showed that ketoacidosis may develop rapidly in association with infection, ${ }^{4}$ and Peden et al suggested that ketoacidosis is more common in diabetics treated by continuous subcutaneous infusion of insulin. ${ }^{5}$ The onset of ketoacidosis tends to be accelerated during pregnancy, so that this patient probably became ketotic, after accidental cessation of insulin infusion, even more rapidly than she would have in the non-pregnant state. The consequences, of course, were much more serious.

1 Cohen AW, Liston RM, Mennuti MT, Gabbe SG. Glycemic control in pregnan diabetic women using a continuous subcutaneous insulin infusion pump. J Reprod Med 1982;27:651-4 Steel JM, Johnstone FD, Smith AF, Duncan LJP. Five years' experience of a
"prepregnancy" clinic for insulin dependent diabetics. Br Med $\mathcal{J} 1982 ; 285$
$353-6$.

3 Pickup JS, Viberti GC, Bilous RW, et al. Safety of continuous subcutaneous insulin infusion: metabolic deterioration and glycaemic autoregulation after deliberate cessation of infusion. Diabetologia 1982;22:175-9.

4 Boulton AJM, Knight G, Drury J, Ward JD. Diabetic ketoacidosis associated with outpatient treatment using continuous subcutaneous insulin infusion. Postgrad Med J 1983;59:438-9.

Peden NR, Braaten JT, McKendry JBR. Diabetic ketoacidosis during long term 7:1-5.

(Accepted 18 February 1985)

Royal Infirmary, Edinburgh EH3 9YW

J M STEEL, MB, FRCPED, associate specialist in diabetics

Simpson Memorial Maternity Pavilion, Edinburgh EH3 9EF

C P WEST, MB, MRCOG, senior lecturer

Correspondence to: Dr J M Steel. 